Journal of Engineering and Applied Sciences 15 (6): 1306-1310, 2020

ISSN: 1816-949X

(C) Medwell Journals, 2020

\title{
Energy Management and Saving Strategy using HVAC System in University Building
}

\author{
Bashar Mahmood Ali and Ali Kemal ÇAKIR \\ Department of Management Engineering, Faculty of Engineering, \\ Kastamonu University, Kastamonu, Turkey
}

\begin{abstract}
The growing demands for energy usage and better indoor environment quality have motivated in searching for the modern solutions on energy efficiency, electricity consumption and conservation in buildings. The building sector being the largest consumer of electric energy represents a major potential contributor for reducing energy consumption. For such purpose, Building Energy Management System (BEMS) is considered as the latest idea of energy. In this study an attempt is made to measure and evaluate the existing indoor comfort parameters which is focusing on the College of Art, Mosul University, Iraq. The building case studies used in this studydemonstrated how the strategy can be emulated. The physical parameter conditions are then compared with the current ASHRAE Standard-55. These strategies provide practical implications for facility managers to engage the building occupants in working together to achieve energy reductions.
\end{abstract}

Key words: Building management, energy consumption, visual analytics, reductions, implications, facility

\section{INTRODUCTION}

Today, demand for electricity is increasing due to population growth and improved living standards worldwide. Most power plants use fossil fuels to produce electricity, leading to higher energy prices and increased pollution (Rezeka et al., 2015). The level of global warming, declining fossil fuel resources and rising energy costs all have harmful effects in today's society. Various efforts are being made to improve energy efficiency worldwide (Hassan et al., 2009).

One of the hardest problems in achieving energy efficiency is to reduce the energy costs of a building when energy costs are taken into account as part of the general overhead. Building energy auditing is therefore, one of the approaches reviewed and implemented to reduce energy costs. Energy auditing has been recognized as an effective tool that can help people who want to achieve energy-saving plans and energy-saving their goals. Therefore, there are many existing energy auditing solution that might overlook the complicated relationship between the various factors that influence energy consumption buildings (Silva et al., 2010).

One of the main aims of building energy consumption is to ensure thermal comfort conditions in terms of energy consumption. Therefore, there are many existing energy auditing solution that might overlook the complicated relationship between the various factors that influence energy consumption buildings (Silva et al., 2010). Critical evaluation and advanced study are required to provide measures to achieve optimal energy efficiency in buildings. Air Conditioning and Mechanical Ventilation (ACMV) system is the main source of energy consumption for a non-residential building. ACMV systems account for about half of the energy used in buildings (Goetzler et al., 2017).

Nazi et al. (2015) found in his research that standard building can be transformed into low energy office building when the heat gain reduction methodologies drawing from the heat balance analysis can be applied. Hence, designing a sustainable building does not mean that high cost of the technology implementation is in the picture but it is more about selecting the right technologies that can cater well for the building's condition (Nazi et al., 2015).

Shetty et al. (2016) examined to pick up bits of knowledge on the utilization of individual fans regarding temperature, time and different components and information are contrasted and the SET (Standard Effective Temperature). The proposed work recommends rules on fusing tenant inclinations in a decentralized structure for better warm solace and enhanced vitality funds in existing cooled structures. Beginning outcomes uncover that identifying the low-action and high-movement breaks is significant to comprehend the tenant inclinations for the entire working day (Shetty et al., 2016).

Kontes et al. (2017) have defined an experimental simulation protocol involving two office buildings; the buildings have contrasting geometrical and construction characteristics as well as different building services systems for meeting heating and cooling demands, occupant thermal comfort is estimated using the Fanger index as defined in ISO 7730. The results of the parametric study suggest that simple bounds on the dry-bulb air temperature are not sufficient to ensure

Corresponding Author: Bashar Mahmood Ali, Department of Management Engineering, Faculty of Engineering, Kastamonu University, Kastamonu, Turkey 
comfort and in many cases, more detailed considerations taking into account building characteristics as well as the types of building heating and cooling services are required (Kontes et al., 2017).

At present, the lack of comprehensive university building energy consumption and the encountered problem have been identified due to the insufficient budget and lack experienced of energy management team (Singer and Tschudi, 2009). Thus, it is recommended for a series of building energy management is to ensure in direction with a target for university energy-cost saving, hence, enhancement procedure to prevent energy wastage by providing the means to reduce university energy consumption. Building energy consumption management is considered one of the most important aspects that should be conducted in parallel with sustainability university campus. Within this context, the implementation of building energy evaluation will enhance knowledge and awareness for energy and non-energy benefits. In order to achieve thermal comfort in the building and to choose the best strategies for this building, this study aims to conduct a building energy use analysis.

\section{MATERIALS AND METHODS}

The field study was conducted at the College of Art, Mosul University, Iraq. Physical parameters measurement has been conducted in order to evaluate temperature and relative humidity. In order to document the function, the quantitative analysis have been applied. The quantitative analyses consist of detailed continuous measurements of the indoor environment quality (air velocity, operating temperature, relative humidity, air flow rate) and the energy consumption (Fig. 1).

Energy data analysis: Electric power is the main source for current provisions to buildings. Analysis of the pattern of the total energy used is based on the use of electricity. Based on the graph in Fig. 2, most of the energy consumption was decreased in January until February and July until August. Referring to the university academic calendar, semester break occurs twice in a year from January until February and July until August. Therefore, this is the primary source energy consumption reducing during period. In year 2018, the energy consumption was increased compared with the year 2017. This is because of more of the classes being held due to the student intake increment.

Energy consumption for each floor in College of Art, Mosul University, Iraq: Table 1 shows the energy consumption per-day, per-week, per-month and year in KW per hour. The first floor consumes more electricity compare with other floors due to the increase of students who are on the first floor as well as the high consumption of electricity from air conditioning many computers others devices and lighting.

Building energy index: Building energy index is used to assess how much energy use more than $1 \mathrm{~m}$ from buildings. Figure 3 shows the building energy index compare 2017 and 2018. Figure 3 shows that for both year (2017 and 2018) the building energy index is less as

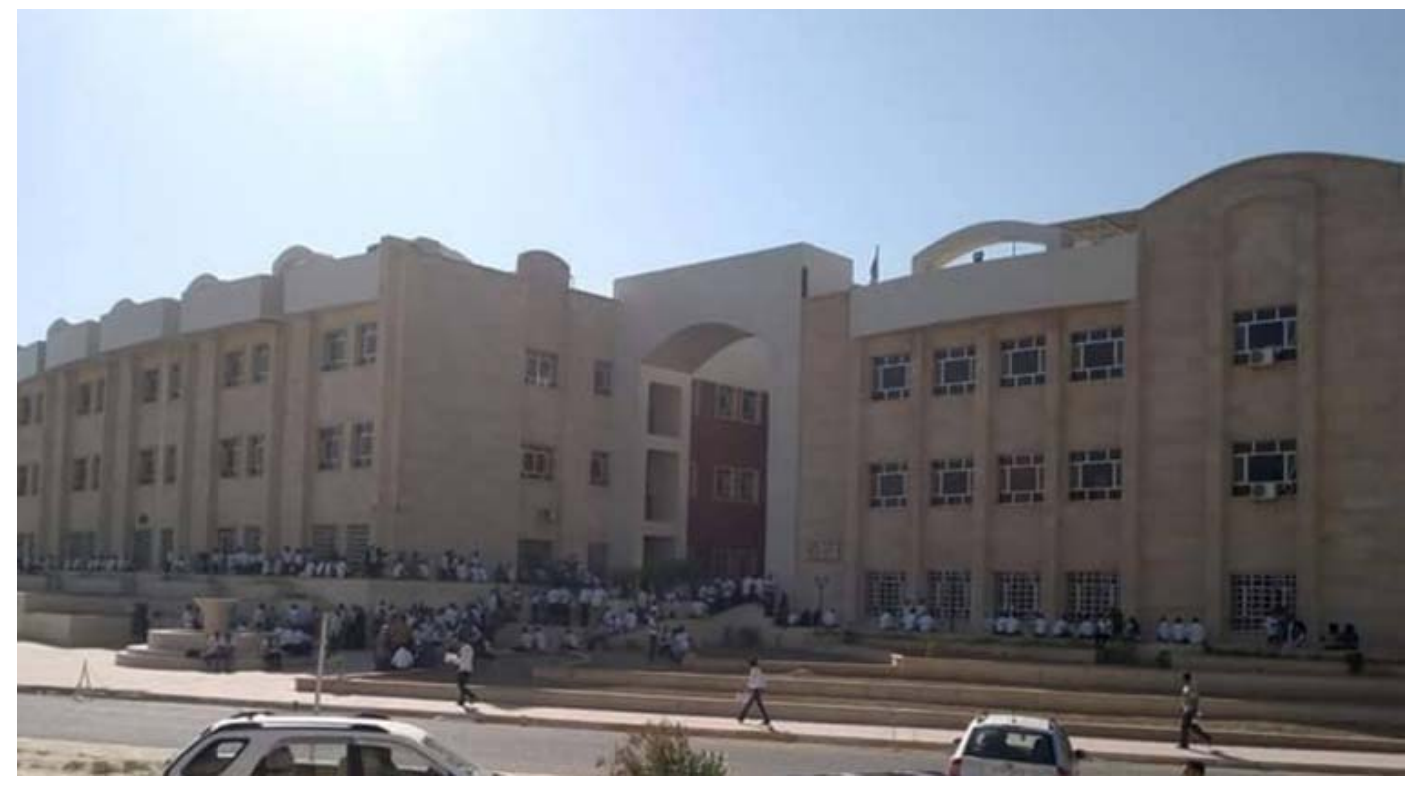

Fig. 1: College of Art, Mosul University, Iraq 
Table 1: Energy consumption (per day/per week/per month/per year)

\begin{tabular}{|c|c|c|c|c|c|}
\hline Floor & $\begin{array}{c}\text { Total consumption } \\
(\mathrm{kWh})\end{array}$ & $\begin{array}{l}\text { Total consumption } \\
\text { in a day }(11 \mathrm{~h})(\mathrm{kWh})\end{array}$ & $\begin{array}{l}\text { Total consumption in } \\
\text { a week ( } 5 \text { days) (kWh) }\end{array}$ & $\begin{array}{l}\text { Total consumption in a } \\
\text { month ( } 4 \text { weeks) (kWh) }\end{array}$ & $\begin{array}{l}\text { Total consumption in a } \\
\text { year ( } 12 \text { months) }(\mathrm{kWh})\end{array}$ \\
\hline Ground & 248.7992 & 2736.7912 & $13,683.956$ & $54,735.824$ & $656,829.888$ \\
\hline First & 338.5355 & $3,723.8905$ & $18,619.4525$ & $74,477.81$ & $893,733.72$ \\
\hline Second & 310.3477 & $3,413.8247$ & 17069.1235 & $68,276.494$ & $819,317.928$ \\
\hline Third & 235.1308 & $2,586.4388$ & $12,932.194$ & $51,728.776$ & $620,745.312$ \\
\hline
\end{tabular}

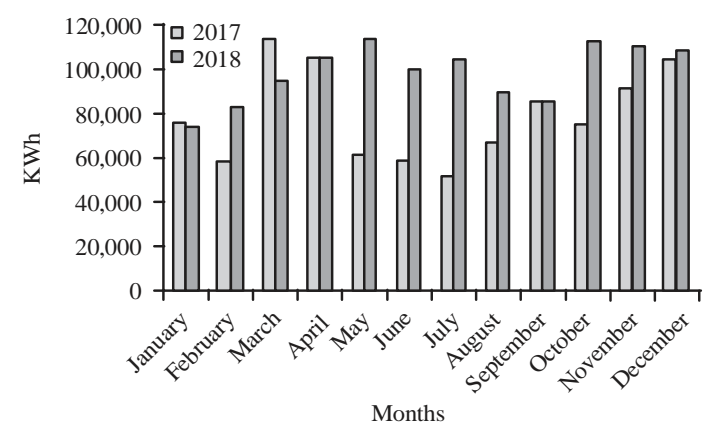

Fig. 2: Comparison between years 2017 and 2018 demand

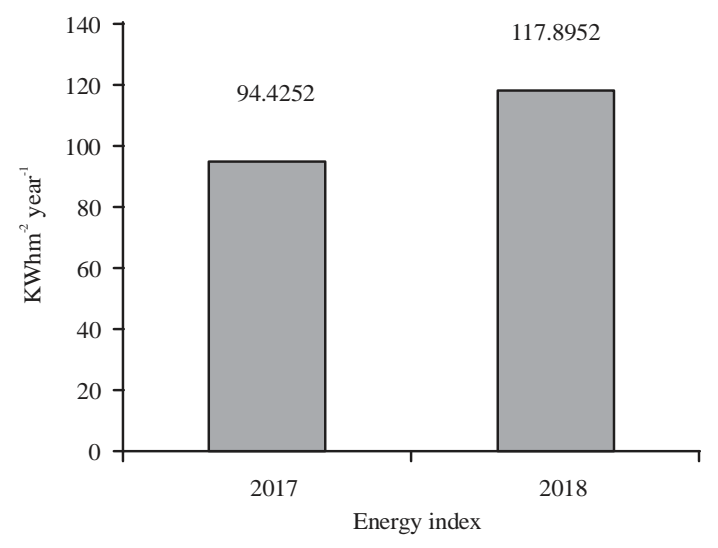

Fig. 3: Building energy index compare between 2017 and 2018

recommended by standard building energy index. The reason for having a good control of energy consumption by switching off the lighting as well as air conditioning in rooms and unused halls.

\section{RESULTS AND DISCUSSION}

The result of measurements had been conducted in the field survey in the three floors of the building. The data collected were included: average air velocity $\left(\mathrm{msec}^{-1}\right)$, average operating temperature $\left({ }^{\circ} \mathrm{C}\right)$ and average relative humidity (\%). Data collection and measurements for each floor of the building had been done during day from $8 \mathrm{am}$ to $6 \mathrm{pm}$. The measurement has been repeated for three times at (8:30-10:00 am, 12:00-2:00 pm and 4:00-6:00 pm).

Average air velocity $\left(\mathrm{msec}^{-1}\right)$ : Good indoor air velocity is very important as people spend more than $90 \%$ of their time indoors. Identify positive and negative forms of air movement in the space. Classroom, office and reading room are the most common place that students and staffs have spent their time during a day; therefore, good indoor air quality is necessary to their well being. Table 2 below shows the measurement results of the average air velocity for each floor of the building.

The results showed that during 8:30-10:00 am, the maximum average air velocity was recorded at third floor $\left(0.128 \mathrm{msec}^{-1}\right)$ followed by second floor $\left(0.093 \mathrm{msec}^{-1}\right)$ while the minimum average air velocity was recorded at ground floor $\left(0.075 \mathrm{msec}^{-1}\right)$. It can be seen that, ground floor, first floor, second floor and third floor average air velocity below the ASHREA:55 Standard.

Average operating temperature $\left({ }^{\circ} \mathbf{C}\right)$ : The temperature is a main and direct effect in thermal comfort an indoor environmental quality. The body of human is removing the heat by air passing over the skin. When the air temperature is higher than the recommended standard, the skin temperature will increase, hence, the body can't be cool and occupants will feel discomfort. Table 3 shows the measurement results of the average operating temperature for each floor of the building.

The results showed that during 8:30-10:00 am, the maximum average temperature was recorded at third floor $\left(24.45^{\circ} \mathrm{C}\right)$ while the minimum average temperature was recorded at first floor $\left(23.24^{\circ} \mathrm{C}\right)$. This study identifies positive forms of temperature in the library during day. It can be seen that ground floor, first floor, second floor and third floor the average operating temperatures within ASHREA:55 Standard.

Average relative humidity (\%): Humans are sensitive to humid air because the human body uses evaporative cooling as the primary mechanism to regulate temperature. Higher relative humidity reduces the effectiveness of sweating in cooling the body by reducing the rate of evaporation of moisture from the skin. Air conditioning reduces discomfort in the summer not only by reducing temperature but also by reducing humidity. Table 4 shows the measurement results of the average relative humidity (\%) for each floor of the building.

The results showed that during 8:30-10:00 am, the maximum average humidity was recorded at third floor (65.96\%) while the minimum average humidity was recorded at first floor (60.23\%). This study identifies positive and negative forms of humidity in the library 
J. Eng. Applied Sci., 15 (6): 1306-1310, 2020

Table 2: The average air velocity $\left(\mathrm{msec}^{-1}\right)$ for each floor

\begin{tabular}{|c|c|c|c|c|c|}
\hline Floor & 8:30-10:00 am & $12: 00-2: 00 \mathrm{pm}$ & 4:00-6:00 pm & Average & ASHREA:55 $\left(0.15-0.5 \mathrm{msec}^{-1}\right)$ \\
\hline Ground & 0.075 & 0.118 & 0.093 & 0.095333 & Below standard \\
\hline First & 0.118 & 0.093 & 0.128 & 0.137000 & Below standard \\
\hline Second & 0.093 & 0.128 & 0.144 & 0.131333 & Below standard \\
\hline Third & 0.128 & 0.144 & 0.139 & 0.137000 & Below standard \\
\hline
\end{tabular}

Table 3: The average operating temperature $\left({ }^{\circ} \mathrm{C}\right)$ for each floor

\begin{tabular}{lccccc}
\hline Floor & $8: 30-10: 00 \mathrm{am}$ & $12: 00-2: 00 \mathrm{pm}$ & $4: 00-6: 00 \mathrm{pm}$ & Average & ASHREA:55 $\left(22-26^{\circ} \mathrm{C}\right)$ \\
\hline Ground & 23.97 & 23.24 & 23.55 & 23.58667 & Within standard \\
First & 23.24 & 23.55 & 24.45 & 23.90333 & Within standard \\
Second & 23.55 & 24.45 & 24.19 & 21.93000 & Within standard \\
Third & 24.45 & 24.19 & 23.07 & 23.90333 & Within standard \\
\hline
\end{tabular}

Table 4: The average relative humidity (\%) for each floor

\begin{tabular}{|c|c|c|c|c|c|}
\hline Floor & 8:30-10:00 am & $12: 00-2: 00 \mathrm{pm}$ & 4:00-6:00 pm & Average & ASHREA:55 (30-60\%) \\
\hline Ground & 65.91 & 60.23 & 65.06 & 63.73333 & Above standard \\
\hline First & 60.23 & 65.06 & 65.96 & 66.61667 & Above standard \\
\hline Second & 65.06 & 65.96 & 70.22 & 61.00333 & Above Standard \\
\hline Third & 65.96 & 70.22 & 63.67 & 61.66000 & Above Standard \\
\hline Floor & $8: 30-10: 00 \mathrm{am}$ & $12: 00-2: 00 \mathrm{pm}$ & $4: 00-6: 00 \mathrm{pm}$ & Average & ASHREA:55 (7.5-10 CFM \\
\hline Ground & 65.91 & 60.23 & 65.06 & 63.73333 & Within standard \\
\hline First & 60.23 & 65.06 & 65.96 & 66.61667 & Within standard \\
\hline Second & 65.06 & 65.96 & 70.22 & 61.00333 & Above standard \\
\hline Third & 65.96 & 70.22 & 63.67 & 61.66000 & Within standard \\
\hline
\end{tabular}

during day. It can be seen that ground floor, first floor, second floor, third floor humidity above the standard for ASHREA:55 Standard.

Average air flow (CFM): The average indoor airflow rate (CFM) for each person in the zones is an important parameter for the indoor environmental quality parameters. In the case, the indoor air flow rate (CFM) for each person decreases that leads to discomfort for the occupants and hard breathing. In the other hand, the indoor air flow rate (CFM) for each person increases that means the energy consumption will increase. Table 5 below shows the measurement results of the average air flow rate for each floor of the library building.

The results showed that during 8:30-10:00 am, the maximum average airflow was recorded at second floor (11.412 CFM) while the minimum average temperature was recorded at first floor (9.953 CFM). This study identifies positive and negative forms of air flow in the library during day. It can be seen that ground floor, first floor and third floor the average air flow within the ASHREA:55 Standard while second floor average air flow above the ASHREA:55 Standard.

The result of this study based on the finding by analyzed physical parameter measurements data through different graphs and tables. The physical parameters of the College of Art, Mosul University, Iraq building are average air velocity, average operating temperature, average relative humidity, average flow. The duration was 8:30-10:00 am, 12:00-2:00 pm and 4:00-6:00 pm. Below are the details for physical parameter results and comparison with standards:
- The average air velocity was recorded $\left(0.1251665 \mathrm{msec}^{-1}\right)$

- The average air flow was recorded (9.95200025 CFM)

- $\quad$ The average operating temperature $\left(23.3308325^{\circ} \mathrm{C}\right)$

- The average relative humidity (63.2533325\%)

\section{CONCLUSION}

According to above results, it is proven that the indoor thermal quality for operating temperature and relative humidity of the building is poor. Students/lecturers are not satisfied with the thermal condition of the College of Art, Mosul University, Iraq. The building has meagre ventilation and less air change than the recommended level. Also, the above-mentioned difficulties are creating health issues. Air movement can decrease the discomfort caused by thermal sources. This can be achieved through various parameters increasing the window size is one of the recommendations.

The physical indoor environmental conditions not between the ranges of standard which directly effect on the thermal comfort are temperature and air velocity. It can be deduced that the operating temperature is above than the required thermal comfort level and sometimes the occupants feel hot. If the operating temperature changes up or down than the standards, leads to more changes in the thermal comfort. On the other hand, the air velocity is also less than the recommended standard ranges, leading to less air flow and hot. Below are the details for physical parameter results and comparison with standards: 
- The average air velocity was recorded $\left(0.1251665 \mathrm{msec}^{-1}\right)$ less than ASHRAE:55 Standard $\left(0.15-0.50 \mathrm{msec}^{-1}\right)$

- $\quad$ The average air flow was recorded (9.95200025 CFM) within ASHRAE:55 Standard (7.5-10 CFM)

- The average operating temperature $\left(23.3308325^{\circ} \mathrm{C}\right)$, within the range of the ASHREA:55 Standard $\left(22-26{ }^{\circ} \mathrm{C}\right)$

- The average relative humidity (63.2533325\%), above the range of ASHREA:55 Standard (30-60\%)

\section{RECOMMENDATION}

This study is helpful to promote the construction of energy analysis reports as a manual for potential research and development. This research relies on energy consumption and comparison physical parameters with inner environmental quality feature. This research can also be used as a guide for extending the duration of energy analysis using the most suitable and advanced instrument, thus unable to discover more precise data and extensive energy audit during the construction procedure. This research is linked to professionals who need data on the value of the locked environment as such as well as instructions for those who want to measure the value of the indoor environment.

\section{REFERENCES}

Goetzler, W., R. Shandross, J. Young, O. Petritchenko, D. Ringo and S. McClive, 2017. Energy savings potential and RD\&D opportunities for commercial building HVAC systems (No. DOE/EE-1703). Navigant Consulting, Burlington, Massachusetts, USA. https://www.osti.gov/biblio/1419622.
Hassan, M.G., R. Hirst, C. Siemieniuch and A.F. Zobaa, 2009. The impact of energy awareness on energy efficiency. Int. J. Sustainable Eng., 2: 284-297.

Kontes, G.D., G.I. Giannakis, P. Horn, S. Steiger and D.V. Rovas, 2017. Using thermostats for indoor climate control in office buildings: The effect on thermal comfort. Energies, Vol. 10, No. 9. 10.3390/en10091368

Nazi, W.I.W., Y.D. Wang and T. Roskilly, 2015. Methodologies to reduce cooling load using heat balance analysis: A case study in an office building in a tropical country. Energy Procedia, 75: 1269-1274.

Rezeka, S.F., A.H. Attia and A.M. Saleh, 2015. Management of air-conditioning systems in residential buildings by using fuzzy logic. Alexandria Eng. J., 54: 91-98.

Shetty, S.S., H.D. Chinh, M. Gupta and S.K. Panda, 2016. Personal thermal comfort management in existing office buildings using energy-efficient fans. Proceedings of the IECON 2016 42nd Annual Conference on IEEE Industrial Electronics Society, October 23-26, 2016, IEEE, Florence, Italy, pp: 7083-7088.

Silva, P.C.P.D., S.M. Silva, M.G.D. Almeida and L. Braganca, 2010. Portuguese EPBD based regulation put side by side with energy simulation tools. Proceedings of the EuroSun 2010 International Scientific Conference on Solar Heating, Cooling and Buildings, September 28 October 1, 2010, Institut fur Nachhaltige Technologien, Graz, Austria, pp: 1-8.

Singer, B.C. and W.F. Tschudi, 2009. High performance healthcare buildings: A roadmap to improved energy efficiency. Lawrence Berkeley National Laboratory, California. https://indoor.lbl.gov/publications/highperformance-healthcare-buildings 